\title{
POLÍTICA PÚBLICA DE FORMAÇÃO NO TRABALHO DOCENTE DO PROFESSOR INICIANTE DE EDỦCAÇÃO FÍSICA
}

\author{
Leandro Oliveira Rocha \\ Universidade Federal do Rio Grande do Sul, Porto Alegre, Rio Grande do Sul, Brasil \\ Fabiano Bossle \\ Universidade Federal do Rio Grande do Sul, Porto Alegre, Rio Grande do Sul, Brasil \\ Vicente Molina Neto \\ Universidade Federal do Rio Grande do Sul, Porto Alegre, Rio Grande do Sul, Brasil
}

\begin{abstract}
Resumo
Este estudo busca compreender a relação entre a política pública de formação de professores vigente e o trabalho docente do professor iniciante de Educação Física. Trata-se de uma etnografia crítica realizada em três escolas, com três professores iniciantes de Educação Física, cujos principais instrumentos utilizados foram: observação participante, diálogos, entrevista e análise documental. Identificamos que a política pública de formação de professores visa melhorar o ensino na Educação Básica e que essa meta não tem sido concretizada, uma vez que as relações estabelecidas com outros professores, direção e entornos da profissão são mais significativas e não têm contribuído para a manutenção da resiliência e rigorosidade metódica.

Palavras-chave: Política pública de formação de professores. Professor iniciante. Educação Física. Etnografia.
\end{abstract}

\section{Introdução}

Este texto é parte do relatório de uma investigação ${ }^{61}$ apresentada ao Programa de PósGraduação em Ciências do Movimento Humano da Escola de Educação Física da Universidade Federal do Rio Grande do Sul (PPGCMH-UFRGS), cujo problema de pesquisa foi sintetizado na seguinte questão: Como a política pública de formação de professores vigente é concretizada no trabalho docente do professor iniciante de Educação Física da Educação Básica de Lajeado?

Compreendemos, por iniciante, o professor diplomado com tempo de docência de um a cinco anos de trabalho docente (MARCELO, 2009). Estudar o professor iniciante no contexto deste

${ }^{61}$ O presente trabalho não contou com apoio financeiro de nenhuma natureza para sua realização 
estudo justifica-se, pois, os primeiros anos de trabalho docente são, geralmente, marcados por situações de tensão e conflito, que podem deixar o professor iniciante no dilema de permanecer ou abandonar a docência (HUBERMAN, 2007; SOUZA, 2009), e carregados de intensos aprendizados sobre a docência e a profissão, que são fundamentais para manter o professor motivado e comprometido com seu trabalho (DAY; GU, 2012).

Diante do exposto, o tema deste estudo, concentrado na política pública de formação de professores, visa identificar a distância entre o que é preconizado pelo Estado e o que ocorre onde essa política é experienciada, a fim de possibilitar a reflexão acerca de seus impactos e efeitos sobre a vida das pessoas ou dos grupos sociais vinculados a ela. (KLEIN; DAMICO, 2012).

Assim, para identificar a relação entre a política pública de formação de professores e o trabalho dos professores iniciantes de Educação Física, localizamos, inicialmente, os programas políticos federais constitutivos da atual política pública federal de formação, os quais foram organizados em três grupos, apresentados a seguir:

(a) Programas de expansão do ensino superior: visam aumentar a oferta do ensino superior para atender a exigência de certificação de professores da Educação Básica em serviço (BRASIL, 1996), bem como fomentar a educação especial, de jovens e adultos, indígena, do campo e de populações em situação de vulnerabilidade social. Programas como o Sistema Universidade Aberta do Brasil (UAB) e Política Nacional de Formação de Profissionais do Magistério da Educação Básica (Parfor) fazem parte desse grupo.

(b) Programas de democratização da oferta: englobam os programas cuja finalidade é potencializar a formação inicial de brasileiros com baixa renda financeira, visando, dessa forma, contribuir para minimizar os efeitos das desigualdades de oportunidades. Esse grupo é constituído pelo Fundo de Financiamento ao Estudante do Ensino Superior (Fies), pelo Programa Universidade para Todos (ProUni), pelas Leis de Cotas Raciais para ingresso de estudantes em Instituições Públicas de Ensino Superior e pelo Sistema de Seleção Unificada (SiSU).

(c) Programas de qualificação da oferta: visam promover e/ou assegurar a qualidade da formação inicial, por meio da avaliação do ensino superior, apoio financeiro às Instituições de Ensino Superior (IES) públicas e bolsas de pesquisa e extensão aos estudantes. Esse grupo é formado pelos seguintes programas: Sistema Nacional de Avaliação da Educação Superior (Sinaes), Programa de Apoio a Planos de Reestruturação e Expansão das Universidades Federais (Reuni), Programa de Consolidação das Licenciaturas (Prodocência), Programa de Educação Tutorial (PET), Programa Institucional de Bolsa de Iniciação à Docência (Pibid) e Programa de Extensão Universitária (ProExt).

Paralelamente à localização e organização desses dispositivos legais, compreendemos que a essência conceitual da política pública é o problema público, uma vez que suas principais características são intencionalidade e resposta a um problema de caráter público (SECCHI, 2012). Nesse sentido, ao partirmos do pressuposto de que uma investigação sobre política pública "não prescinde do estudo de um problema que seja entendido como coletivamente relevante" (SECCHI, 2012, p. 7), identificamos que, de forma geral, a atual política pública de formação busca enfrentar a baixa qualidade técnico-científica do trabalhador brasileiro. Nesse contexto, no que tange à formação de professores, seu principal objetivo é melhorar a qualidade do ensino da Educação Básica, uma vez que, conforme as considerações de Day e Gu (2012), os diferentes cenários educacionais de cada país em comum são produzidos porque os governos acreditam que, ao 
intervirem nas reformas escolares, poderão elevar os níveis de rendimento dos alunos e, de algum modo, aumentar a competitividade econômica do país no mercado global.

Sendo assim, organizamos este artigo em três seções: as decisões metodológicas, a análise das informações e as considerações finais, contendo aprendizagens que construímos durante a realização desta investigação.

\section{Decisões metodológicas}

Para desenvolver esta pesquisa, realizamos uma etnografia crítica, tendo em vista que a etnografia promove a interativa entre os sujeitos envolvidos no processo de investigação e - muito por isso - é geralmente utilizada nos estudos que se propõem a compreender fenômenos complexos e subjetivos, como os que acontecem no âmbito da escola (OLIVEIRA; SILVA; MOLINA NETO, 2011). Seu principal objetivo é compreender os significados atribuídos pelos sujeitos investigados ao que vivenciam, por isso há extrema importância em descrever com profundidade as situações, pessoas, ambientes, depoimentos e diálogos, tornando-se, o pesquisador, o principal instrumento na coleta e análise das informações (NEGRINE, 2010; ANDRÉ, 1998).

A etnografia crítica, por sua vez, mantém as mesmas características e procedimentos das etnografias. Contudo, sustenta-se nas referências teóricas da tradição crítica, procura identificar situações de injustiça e de opressão que se estabelecem no contexto social, promover "o exercício do pensamento dialético" (MOLINA NETO, 2010, p. 122), "libertar o objeto de análise da tirania de categorias fixas, inatacáveis, e repensar a própria subjetividade como um engajamento narrativo, parcial, permanentemente aberto com o texto e com o contexto" (KINCHELOE; MCLAREN, 2006, p. 303).

No que se refere ao modo como foi construída, esta etnografia caracteriza-se como uma bricolagem, termo inicialmente utilizado por Lévi-Strauss (1989) para descrever o componente espontâneo das ações do etnógrafo e incluir, nessas ações, o caráter de "artesanato", por meio do qual o etnógrafo está apto a empregar um grande número de tarefas diversificadas e práticas interpretativas, sem que estas sejam necessariamente definidas com antecedência. O etnógrafo, visto como um bricoleur, utiliza as ferramentas estéticas e materiais do seu ofício "empregando efetivamente quaisquer estratégias, métodos ou materiais empíricos que estejam ao seu alcance, pois, havendo a necessidade de que novas ferramentas ou técnicas sejam inventadas ou reunidas, assim o pesquisador o fará". (DENZIN; LINCOLN, 2006, p. 19). Logo, a etnografia vale-se de um processo interativo influenciado pela história pessoal, gênero, classe social, raça e etnicidade das pessoas que fazem parte do cenário, e pode ser interpretada como um processo de artesanato cultural, no qual cada pesquisador a desenha de uma forma para poder descrever a cultura (DENZIN; LINCOLN, 2006).

O trabalho de campo teve início com a realização de um estudo preliminar, em maio de 2012, que consistiu no levantamento de informações quanto ao tempo de trabalho docente dos professores de Educação Física das redes de ensino municipal, estadual e particular de Lajeado, município localizado no estado do Rio Grande do Sul (RS). Por meio desse estudo, identificamos somente três professores de Educação Física iniciantes, que consentiram em participar da pesquisa 
por meio de suas assinaturas no Termo de Consentimento Livre e Esclarecido (TCLE). São eles: a professora Júlia ${ }^{62}$, formada em agosto de 2006, com contrato temporário de 20 horas semanais em uma escola estadual e 3 anos de docência; o professor Sílvio, formado em fevereiro de 2010, com contrato de 10 horas semanais em uma escola particular e 3 anos de docência; e o professor Rafael, formado em agosto de 2011, com contratado de 20 horas semanais em uma escola particular e 3 anos de docência. No mês de junho de 2012, nos apresentamos à escola e obtivemos o consentimento para realizar a etnografia, que se estendeu ao longo dos meses de julho a dezembro de 2012.

Os instrumentos de coleta das informações utilizados foram: a observação participante; os diálogos; o diário de campo; as entrevistas com os três professores colaboradores da pesquisa e com o coordenador do curso de Educação Física/Licenciatura da IES formadora desses três professores; os questionários com os professores colaboradores, diretores e supervisores pedagógicos das escolas pesquisadas; e análise de documentos, como os Planos de Estudos da Educação Física e o Projeto Político Pedagógico das escolas pesquisadas.

As observações participantes, realizadas em um período de seis meses, totalizaram 69 idas às escolas, aproximadamente 230 horas de observação. Procuramos descrever e anotar fielmente, em diários de campo (quatro cadernos), o cotidiano de trabalho nas escolas, as atividades laborais desenvolvidas pelos professores colaboradores e as falas dos professores, procurando não emitir qualquer juízo de valor.

O processo de análise e interpretação das informações foi pautado nas "influências críticas", ou seja, nos significados atribuídos pelos próprios professores colaboradores a acontecimentos provenientes do cotidiano de trabalho (DAY; GU, 2012). Tais significados são configurados pela soma entre cotidiano de trabalho e contextos pessoais do próprio professor e mobilizam o modo como este percebe a docência, a profissão, a escola e desenvolve seu trabalho (DAY; GU, 2012). Assim, ao triangularmos as informações coletadas pelos diferentes instrumentos de coleta de informações emergiram as quatro categorias de análise da pesquisa, cujas reflexões são apresentadas a seguir.

\section{Análise das informações}

$\mathrm{Na}$ primeira categoria de análise, intitulada "Trabalho, influências e aprendizados dos professores colaboradores", descrevemos e analisamos as tarefas laborais e práticas pedagógicas desenvolvidas pelos professores colaboradores, a partir das quais identificamos que os aprendizados construídos ao longo dos primeiros três anos de trabalho docente, frutos das relações estabelecidas no cotidiano da escola e com os entornos da profissão, orientam o modo como atuam profissionalmente e percebem a docência.

Para ilustrar o que acontece, o professor colaborador Sílvio, por exemplo, desistiu do planejamento escrito porque entende que isso é perda de tempo, desenvolve aulas sem sequência pedagógica definida, presta mais atenção no controle do tempo da aula e nas atitudes de alunos do

${ }^{62}$ Os nomes dos professores colaboradores e das escolas pesquisadas são fictícios. 
que no conteúdo das aulas e prefere não se envolver com a gestão da escola, mesmo quando é convidado, porque entende que tal envolvimento é somente sobrecarga de trabalho. A professora colaboradora Júlia, por sua vez, demonstra desilusão com a escola pública estadual devido ao baixo salário e às condições precárias da estrutura física destinada às aulas de Educação Física, desenvolve aulas de forma improvisada e sem intencionalidade pedagógica quando está sobrecarregada de tarefas escolares (passou a utilizar o momento da aula para corrigir avaliações e preencher os diários de classe) e não se posiciona criticamente nas reuniões da escola para evitar conflitos que possam lhe prejudicar. Já o professor colaborador Rafael, embora cuidadoso com os planos de estudos, planejamento das aulas e processo ensino-aprendizagem, atualmente opta pelo individualismo e isolamento, porque não enxerga a importância do trabalho coletivo, preferindo distanciar-se dos demais professores e equipe diretiva, pois percebe que o professor não tem protagonismo nas decisões da escola, bem como não participa das reuniões pedagógicas porque entende que elas pouco contribuem para qualificar suas práticas ensino.

Logo se torna possível dizer que esses três professores iniciantes chegam à escola, ministram as aulas e vão embora, ou seja, os três dedicam-se exclusivamente ao momento das aulas (a hora-aula), não se envolvem nas discussões pedagógicas, nem nos projetos de escola e de secretaria, não trabalham em colegiado e desenvolvem práticas pedagógicas a partir daquilo que acreditam ser o ideal e/ou possível a ser feito.

$\mathrm{Na}$ segunda categoria, "Expansão do ensino superior: acesso ao emprego e expectativas profissionais", relacionamos os programas de expansão do ensino superior, em meio à reestruturação produtiva capitalista, com a flexibilização do emprego e o processo de desvalorização do magistério.

Para compreender tal relação, é fundamental entender que a reestruturação produtiva do capital reorganizou o mercado de trabalho, fomentou a flexibilização dos vínculos empregatícios e corroborou para a mercantilização do ensino (BALL, 2004; 2011). No Brasil, a política neoliberal, iniciada na segunda metade da década de 1980, foi estendida à esfera das universidades brasileiras, alavancando o abandono do ensino universitário público (PAULA, 2009) e fazendo com que os processos educativos desse período sofressem ajustes estruturais baseados no enxugamento dos recursos do Estado para a educação, na privatização das instituições de ensino e na criação de novas formas de direcionamento dos recursos públicos, visando à expansão acelerada do ensino superior e o desenvolvimento de um moderno mercado da educação superior (FREITAS, 2003).

A expansão do ensino superior, potencializada na década de 1990 pela relação entre ensino superior, avanços tecnológicos e política neoliberal, demarcou a fase produtivista da educação superior (SAVIANI, 2006) e promoveu uma verdadeira corrida pelo diploma iniciada no ano de 1999 (ANFOPE, 2000). Explica a Anfope (2000, p. 21) que a expansão do ensino superior mobilizou muitos cursos de formação de professores que se tornaram verdadeiras "fábricas de diplomas" preocupadas com a mera certificação e/ou diplomação. Isso, mais tarde, corroborou para promover a superexploração do trabalho docente, desvalorização do magistério e ampliação dos contratos temporários (ANFOPE, 2000).

Em meio a esse contexto, os programas de expansão do ensino superior, embora fundamentais para promover a equidade do acesso à formação inicial, contribuem para entender o modo como os professores colaboradores ocuparam seus postos de trabalho e suas atuais expectativas profissionais. No caso da professora Júlia, o Fies foi fundamental para concluir sua formação inicial; contudo, depois de diplomada, ficou três anos procurando emprego, deixando 
currículos em escolas e atuando fora da área da Educação Física, até ser contratada temporariamente pela rede estadual. Em situação oposta, os professores Sílvio e Rafael foram contratados pelas escolas particulares antes de diplomados, devido à vaga de emprego que surgiu no período em que estavam realizando atividades acadêmicas nas escolas.

Nesse contexto, porém, o contrato de trabalho, sem garantia de permanência no emprego, mobiliza os professores colaboradores a perceberem a escola como mais uma opção de trabalho dentre outras possibilidades e eleva-os, mesmo expressando satisfação pela docência, a direcionar suas expectativas profissionais à área não escolar e atividades laborais mais rentáveis financeiramente. Um exemplo dessa situação é o professor Rafael, que sempre quis ser professor de Educação Física escolar, mas, depois de atuar em academias de musculação e hidroginástica, passou a repensar suas metas profissionais.

Tais situações permitem-nos dizer que o acesso ao emprego, para esses professores, é uma questão de estar no lugar certo no momento certo, aspecto que relacionamos ao alerta de Dubar (2009, p. 226), segundo o qual: "como construir projetos profissionais quando nos arriscamos a ficar expostos a eventualidades permanentes, e os comportamentos oportunistas podem tornar-se os mais gratificantes?".

Nesse sentido, entendemos que a flexibilização dos vínculos empregatícios e a atual desvalorização financeira do magistério são decisivas para compreender o modo como esses professores iniciantes ocuparam seus postos de trabalho e suas atuais expectativas profissionais. Além disso, tais aspectos fazem com que eles compreendam que o trabalho docente é composto pelas tarefas remuneradas, e qualquer outro envolvimento é algo "a mais" e, portanto, desnecessário. Essa compreensão pode ser entendida a partir de Sennett (2009, p. 33), que considera que a flexibilidade dos vínculos empregatícios e a constante possibilidade de mudança de emprego "afrouxa os laços de confiança e compromisso" entre trabalhador e seu local de trabalho.

$\mathrm{Na}$ terceira categoria, denominada "Democratização do acesso ao ensino superior: a fase inicial da vida profissional dos professores colaboradores", analisamos o acolhimento da escola aos professores colaboradores, e como a política pública de formação inicial impacta o contexto das escolas.

Diferente do que diz a literatura sobre professor iniciante, que os primeiros anos de docência são identificados como os piores anos da vida profissional (HUBERMAN, 2007), o trabalho docente, para os professores colaboradores, é "tranquilo" e a cada ano que passa se torna mais fácil. Ao aprofundar a análise acerca de tal concepção, identificamos que a tranquilidade expressa é mobilizada pela falta de controle e cobrança das equipes diretivas sobre o que esses professores iniciantes fazem ou não fazem, bem como pela ausência de obrigações para além das aulas, como organização de eventos e participação de reuniões. Tal análise pode ser relacionada ao estudo de Machado et al. (2011, p. 137), segundo o qual "a impressão que se tem é de que, para a escola, basta ao professor de Educação Física a assiduidade e a pontualidade, além do cumprimento de atividades burocráticas, por exemplo, o preenchimento das pautas de chamada".

Além disso, identificamos que a falta de controle e acompanhamento da escola sobre o que esses professores fazem é corroborada pela "hierarquização" dos saberes escolares (GOODSON, 1995), que é potencializada no contexto das escolas pesquisadas pelos programas de democratização do acesso ao ensino superior - com destaque para o Exame Nacional do Ensino Médio (Enem). Nesse caso, tendo em vista que o ensino superior é considerado uma das principais formas de ascensão socioeconômicas e de mobilidade social (OLIVEIRA, 2004; SENNETT, 2009), 
os professores de determinados componentes curriculares são cobrados pela direção quanto ao cumprimento dos conteúdos programáticos, diferente do que acontece com o professor de Educação Física, cujos conteúdos parecem sem relevância para a escola. Tal situação também pode ser relacionada a Machado et al. (2011, p. 138-139), cujos estudos apontam que a "escola possui uma visão acerca da função pedagógica da Educação Física muito distante da perspectiva que a entende como um componente curricular com um saber a ser transmitido/tematizado e que se configura naquilo que se tem denominado de cultura corporal de movimento".

Em linhas gerais, embora a falta de controle e cobrança favoreça a tranquilidade expressa pelos professores colaboradores, em contrapartida denuncia a falta de reconhecimento, acompanhamento e "retro informação", ou seja, a falta de informações fornecidas pelas equipes diretivas que auxiliem os professores iniciantes a pensar suas práticas pedagógicas e compreender o trabalho docente (DAY; GU, 2012, p. 42). Nesse contexto, o que emerge é uma espécie de "círculo vicioso", no qual os professores colaboradores não participam das discussões pedagógicas porque não são reconhecidos e não são reconhecidos porque não participam das discussões pedagógicas. Esse aspecto potencializa uma concepção de Educação Física Escolar limitada ao lazer, entretenimento e disciplina de corpos, que esses professores, iniciantes de Educação Física, não conseguem reverter por falta de entusiasmo ou de apoio institucional.

$\mathrm{Na}$ quarta e última categoria de análise, intitulada "Avaliação institucional: concepções sobre a formação inicial e fomento à qualidade da oferta", analisamos o que esses professores iniciantes de Educação Física pensam sobre a docência e a formação inicial, e identificamos como a atual política pública de formação de professores influencia os processos de ensino na IES onde eles cursaram Educação Física.

Observarmos que os professores colaboradores limitam suas concepções acerca do trabalho docente e da função do professor ao que vivenciam cotidianamente na escola, criticam o distanciamento entre a formação inicial e os enfrentamentos provenientes do cotidiano de trabalho e, dessa forma, desconsideram que a formação inicial integra elementos pessoais, profissionais e sociais e busca contribuir para a formação de um professor autônomo, reflexivo, crítico e colaborador (CUNHA, 2010).

Diante dessa limitação de concepções, identificamos, na IES formadora, que o Pibid é visto como possibilidade para auxiliar os acadêmicos a compreender melhor a escola e o trabalho na escola; mas isso ainda é uma possibilidade, visto que o programa foi recentemente implementado nessa IES. Além desse programa, o Sinaes, por sua vez, consiste na principal estratégia política de assegurar a qualidade da formação inicial, uma vez que, através do Enade ${ }^{63}$, mobiliza reajustes na matriz curricular do curso de Educação Física/Licenciatura; no entanto tal influência não significa a promoção de melhorias no ensino da Educação Básica porque muitas alterações curriculares visam

${ }^{63}$ O Enade, associado ao Sinaes, visa acompanhar o processo de aprendizagem e o desempenho dos estudantes em relação aos conteúdos programáticos previstos nas diretrizes curriculares do respectivo curso de graduação (BRASIL, 2004). Conforme Fonseca (2008), esse instrumento de avaliação, em especial, trata-se de uma estratégia política com objetivo específico de promover melhorias de caráter pedagógico no processo educativo de nível superior por meio da regulação. Assim sendo, relacionado à perspectiva emancipatória, o Enade é entendido politicamente como propulsor da qualidade da formação inicial por meio da dimensão pedagógica, além de estratégia para certificar a qualidade dos cursos de formação e acionar a responsabilidade da própria IES (FONSECA, 2008). 
apenas qualificar os acadêmicos para responder ao exame, sem qualquer relação com o trabalho docente. Também foi identificado que essa IES tem elaborado suas próprias estratégias para promover um ensino de qualidade, aproximando, por exemplo, os cursos de licenciatura para potencializar o aprendizado do trabalho em colegiado.

Diante dessa iniciativa institucional e relembrando a forma como os professores colaboradores desenvolvem, por várias vezes, práticas pedagógicas apoiadas no conhecimento construído ao longo da formação inicial, entendemos que essa IES parece esforçar-se para cumprir sua função educativa. Porém o cotidiano de trabalho na escola parece mais significativo no que tange ao modo como esses três professores compreendem a docência.

\section{Considerações finais}

Considerando as discussões e interpretações realizadas nas categorias de análise, entendemos, em primeiro lugar, que os documentos governamentais declaram que a atual política pública de formação de professores de nível federal objetiva melhorar a qualidade do ensino na Educação Básica através de incentivos à formação inicial. Percebemos, também, que a atual política pública de formação inicial influencia o contexto singular das escolas e dos processos formativos, porém deve ser analisada levando em conta o contexto social mais amplo e o posicionamento político dos atores sociais, uma vez que são estes que a personalizam.

Compreendemos que a política pública de formação de professores, associada às novas bases de produção do capital e à perspectiva econômico-social em torno da escolarização e do ensino superior, mesmo que não seja sua intenção, contribuiu para firmar, no contexto educacional, o processo de precarização do trabalho docente (OLIVEIRA, 2004) e do emprego (DUBAR, 2009), a intensificação do trabalho docente (HARGREAVES, 2005) e a colonização do tempo de lazer dos professores (TARDIF; LESSARD, 2011). Esses aspectos prejudicam sensivelmente o trabalho dos professores colaboradores e os fazem repensar a docência e suas expectativas profissionais.

Nesse sentido, a falta de tempo livre para usufruir a vida pessoal, a falta de protagonismo nas decisões da escola e o baixo retorno financeiro, somados à falta de desafio e retro informação, fazem com que esses três professores iniciantes não se interessem em participar ativamente da política escolar ou por qualquer outro tipo de envolvimento com a escola para além da hora-aula. Não obstante, esses professores - embora demonstrem gosto e satisfação pessoal pela docência, mobilizada pela alegria proveniente da interação com alunos e do autorreconhecimento de sua importância social - não encontram motivos para investir significativamente na carreira docente e, por vezes, desenvolvem práticas pedagógicas sem intencionalidade pedagógica definida.

Com base nessas considerações, percebemos que a cultura escolar das escolas pesquisadas é mais significativa para os professores colaboradores e faz com que repensem e ressignifiquem a escola, a docência e as tarefas que compõem o trabalho docente, e consequentemente, revejam o modo como atuam profissionalmente na escola. Em outras palavras, diante do que encontram na escola, esses professores talvez se sintam em meio a um conflito: optar pelo que é mais fácil, menos trabalhoso, e pelo isolamento, tal como fazem outros professores de outros componentes curriculares, ou, ao contrário, engajar-se em uma luta solitária e desgastante para tentar promover uma educação com maior qualidade.

Por isso, entendemos que a fase inicial da vida profissional desses três professores iniciantes é marcada por situações que não favorecem sua resiliência e rigorosidade metódica. Entendendo a 
primeira como "produto de disposições de valores pessoais e profissionais, influenciados por fatores organizacionais e pessoais e determinados pela capacidade dos indivíduos de controlar fatores específicos do contexto" (DAY; GU, 2012, p. 183); e a segunda como produção das condições em que aprender criticamente é possível, e que "implicam ou exigem a presença de educadores e de educandos criadores, instigadores, inquietos, rigorosamente curiosos, humildes e persistentes" (FREIRE, 1996, p. 26).

Ao retomar a reflexão acerca das influências da política pública de formação de professores, identificamos que ela, de fato, fomenta a expansão do ensino superior, democratiza o acesso ao ensino superior e pode mobilizar alterações curriculares nas IES. No entanto, em resposta ao problema dessa investigação, entendemos que a política pública de formação de professores vigente não tem contribuído de forma efetiva para melhorar o ensino da Educação Física na Educação Básica nas escolas pesquisadas. Isso nos permite dizer que ela não tem sido concretizada no trabalho docente dos professores iniciantes de Educação Física de Lajeado, algo que sugere que a atual política pública de formação de professores "bate na porta da escola, mas não entra".

Embora a política pública de formação de professores, por si só, não resolva problemas complexos relativos à educação - como a precarização do emprego, baixo valor do piso salarial, carência de planos de carreira, falta de estrutura física e condições de materiais didáticos adequados -, não há como esperar relações diferentes se, politicamente, tem-se buscado qualificar o ensino na Educação Básica por meio da quantificação e regulação dos processos formativos. Logo, pautar a política pública de formação de professores na massificação do ensino superior e avaliação institucional, sem investir nos professores que estão na escola, é permitir que haja uma política pública de formação de professores que não age no cotidiano da escola e, por isso, não contribui para qualificar a Educação Básica como pretende.

Assim sendo, percebemos que é de suma importância utilizar o Enade para fomentar alterações curriculares que priorizem a formação crítica e política do professor, a fim de mantê-los motivados nas fases intermediárias de suas vidas profissionais. Além disso, sugerimos a criação de bolsas de estudo para que professores da própria escola atuem como tutores dos professores iniciantes, algo que pode, inclusive, promover a construção de pequenas comunidades de aprendizado na própria escola (HARGREAVES, 2005).

Do ponto de vista metodológico, a etnografia crítica foi uma decisão correta para a realização da pesquisa, uma vez que a permanência nas escolas e a forma como o trabalho de campo foi realizado - com observações em profundidade e diálogos com professores, supervisores, diretores e outros funcionários das escolas - permitiu identificar elementos da cultura docente dos professores iniciantes de Educação Física de Lajeado e da cultura escolar das escolas pesquisadas. Ao mesmo tempo, por meio da etnografia crítica, compreendemos limites e possibilidades da atual política pública de formação de professores em relação ao que já existe de concreto nas escolas e ao que é compartilhado pelos professores iniciantes no seu cotidiano de trabalho.

Por fim, ao estudar a política pública de formação de professores e construir esta pesquisa, compreendemos que a política pública não pode ser absolutamente abstrata, ao ponto de influenciar o contexto social e não ser concretizada, principalmente porque seu principal objetivo consiste em promover a transformação social, visando o bem público. 


\title{
THE PUBLIC POLICY OF TRAINING FOR THE BEGINNING TEACHERS OF PHYSICAL EDUCATION
}

\begin{abstract}
This study seeks to understand the relationship between the current public policy of teachers training and the work of beginning teachers of Physical Education. It deals with a critical ethnography carried out in three schools with three beginning teachers of Physical Education. Researchers have used the following main tools: participant observation, dialogues, interviews and document analysis. We have identified that the public policy of teachers training aims to improve teaching in Basic Education, and that this goal has not been achieved in the surveyed schools. This so happens because the relationships established with other teachers, the school director, and profession surroundings, are more meaningful and have not contributed to the maintenance of resilience and methodical rigor.
\end{abstract}

Keywords: Public policy of teachers training. Beginning teacher. Physical education. Ethnography.

\section{LA POLÍTICA PÚBLICA DE FORMACIÓN EN EL TRABAJO DOCENTE DEL PROFESOR PRINCIPIANTE DE EDUCACIÓN FÍSICA}

\section{Resumen}

Este estudio busca comprender la relación entre la política pública de formación de profesores vigente y el trabajo docente del profesor principiante de Educación Física. Se trata de una etnografía crítica realizada en tres escuelas, con tres profesores principiantes de Educación Física, cuyos principales instrumentos utilizados fueron: observación participante, diálogos, entrevista y análisis documental. Identificamos que la política pública de formación de profesores visa mejorar la enseñanza en la Educación Básica y que esa meta no ha sido concretizada, una vez que las relaciones establecidas con otros profesores, dirección y entornos de la profesión son más significativas y no han contribuido para la manutención de la resiliencia y rigurosidad metódica.

Palabras-clave: Política pública de formación de profesor. Profesor principiante. Educación Física. Etnografía.

\section{Referências}

ANDRÉ, M. E. A etnografia da Prática Escolar. Campinas: Papirus, 1998.

ANFOPE. Associação Nacional pela Formação dos Profissionais da Educação. Documento Final X Encontro Nacional. Brasília/DF, 10 de agosto de 2000, 47 p. Disponível em http://www.lite.fae.unicamp.br/anfope/menu2/links/documentos_encontrosnacionais.htm Acesso em 14 abril 2013.

BALL, S. J. Performatividade, privatização e o pós-estado do bem-estar. Educação e Sociedade, Campinas, vol. 25, n. 89, p. 1105-1126, Set./Dez. 2004. 
BALL, S. J. Sociologia das políticas educacionais e pesquisa crítico-social: uma revisão pessoal das políticas educacionais e da pesquisa em política educacional. In: Políticas educacionais: questões e dilemas. BALL, S. J.; MAINARDES, J. (Org.). São Paulo: Cortez, 2011, p. 21-53.

BRASIL. Lei n. 9.394, de 20 de dezembro de 1996. Estabelece as diretrizes e bases da educação nacional. Brasília, DF, 1996. Disponível em: http://www.planalto.gov.br/ccivil 03/leis/L9394.htm Acesso em: 15 de janeiro de 2012.

BRASIL. Lei n. 10.861, de 14 de abril de 2004. Institui o Sistema Nacional de Avaliação da Educação Superior - SINAES e dá outras providências. Brasília, DF, 2004. Disponível em: <http://www.planalto.gov.br/ccivil_03/_ato2004-2006/2004/lei/110.861.htm>. Acesso em: 30 abril 2012.

CUNHA, M. I. Lugares de formação: tensões entre a academia e o trabalho docente. In: DALBEN, Â.; DINIZ, J.; LEAL, L.; SANTOS, L. (Org. da coleção). Convergências e tensões no campo da formação e do trabalho docente: didática, formação de professores, trabalho docente. Coleção didática e prática de ensino. Belo Horizonte: Autêntica, 2010, p. 129-149.

DAY, C.; GU, Q. Professores: vidas nuevas, verdades antiguas. Madrid: Narcea, 2012.

DENZIN, N. K.; LINCOLN, Y. S. Introdução: a disciplina e a prática da pesquisa qualitativa. In:__ (Org.). O planejamento da pesquisa qualitativa: teorias e abordagens. Tradução Sandra Regina Netz - Porto Alegre: Artmed, 2006, p. 15-41.

DUBAR, C. A crise das identidades: a interpretação de uma mutação. São Paulo: Editora da Universidade de São Paulo, 2009.

FONSECA, D. G. Implicações do Exame Nacional de Desempenho dos Estudantes (ENADE) no curso de Educação Física do IPA. Tese (doutorado). Universidade do Vale do Rio dos Sinos, Programa de Pós-Graduação em Educação. 2008. 182 f.

FREIRE, P. Pedagogia da autonomia: saberes necessários à prática educativa. 35. ed. São Paulo: Paz e Terra, 1996.

FREITAS, H. C. L. Certificação docente e formação do educador: regulação e desprofissionalização. Educação e Sociedade, Campinas, vol. 24, n. 85, p. 1095-1124, dezembro 2003.

GOODSON, I. A invenção de uma tradição. In: . Currículo: teoria e história. Petrópolis: Vozes, 1995, p. 140.

HARGREAVES, A. Profesorado, cultura y postmodernidad: cambian los tiempos, cambia el professorado. 5. ed. España: Ediciones Morata, 2005. 
HUBERMAN, M. O ciclo de vida profissional dos professores. In: NÓVOA, A. (Org.). Vidas de professores. 2. ed. Porto: Porto Editora, LDA, 2007. p. 31-61.

KINCHELOE, J. L.; MCLAREN, P. Repensando a teoria crítica e a pesquisa qualitativa. In: DENZIN, N.; LINCOLN, Y. (Org.). O planejamento da pesquisa qualitativa: teorias e abordagens. Porto Alegre: Artmed, 2006. p. 281-313.

KLEIN, C.; DAMICO, J. O uso da etnografia pós-moderna para a investigação de políticas públicas de inclusão social. In: MEYER, D. E.; PARAÍSO, M. A. (Org.). Metodologias de pesquisas póscríticas em educação. Belo Horizonte: Mazza Edições, 2012, p. 63-85.

LÉVI-STRAUSS, C. O pensamento selvagem. 8. ed. Tradução: Tânia Pellegrini. Campinas, SP: Papirus, 1989.

MACHADO, T. S.; BRACHT, V.; FARIA, B. A.; MORAES C.; ALMEIDA, U.; ALMEIDA, F. Q. As práticas de desinvestimento pedagógico na Educação Física escolar. Movimento. Porto Alegre, v. 16, n. 02, p. 129-147, abril/junho, 2010.

MARCELO, C. Los comienzos en la docencia: um professor com buenos principios. Professorado. Revista de currículum y formación del professorado. Sevilla. V. 13, n. 1, p. 1-36. 2009.

MOLINA NETO, V. Etnografia: uma opção metodológica para alguns problemas de investigação no âmbito da Educação Física. In: MOLINA NETO, V.; TRIVIÑOS, A. N. S. (Org.). A pesquisa qualitativa na Educação Física: alternativas metodológicas. 3. ed. Porto Alegre: UFRGS/Sulina, 2010. 113-145.

NEGRINE, A. Instrumentos de coleta de informações na pesquisa qualitativa. In: MOLINA NETO, V.; TRIVIÑOS, A. N. S. (Org.). A pesquisa qualitativa na Educação Física: alternativas metodológicas. 3. ed. Porto Alegre: UFRGS/Sulina, 2010, p. 61-93.

OLIVEIRA, D. A. A reestruturação do trabalho docente: precarização e flexibilização. Revista Educação e Sociedade, Campinas, v. 25, n. 89, p. 1127-1144, setembro/dezembro, 2004.

OLIVEIRA, C. F.; SILVA, L. O.; MOLINA NETO, V. Arquitetura escolar e o ensino de educação física: relações (im)possíveis. Pensar a Prática, Goiânia, v. 14, n. 2, p. 1-10, maio/agosto, 2011.

PAULA, M. F. A formação universitária no Brasil: concepções e influências. Avaliação, Sorocaba, SP, v. 14, n. 1, p. 71-84, mar. 2009.

SECCHI, L. Políticas públicas: conceitos, esquemas de análise, casos práticos. São Paulo: Cengage Learning, 2012.

SAVIANI, D. O legado educacional do "longo século XX" brasileiro. In: SAVIANI, D. O legado educacional do século XX no Brasil. Campinas, SP: Autores Associados, 2006. 
SENNETT, R. A corrosão do caráter: as consequências pessoais do trabalho no novo capitalismo. 14. ed. Rio de Janeiro: Record, 2009.

SOUZA, D. B. Os dilemas do professor iniciante: reflexões sobre os cursos de formação inicial. Revista Saber Acadêmico, São Paulo, n. 08, p. 35-45, dezembro, 2009.

Recebido em: 26/10/2014

Revisado em: 12/02/2015

Aprovado em: 02/03/2015

Endereço para correspondência:

vicente.neto@ufrgs.br

Vicente Molina Neto

Universidade Federal do Rio Grande do Sul, Programa de Pós Graduação Em Ciências do Movimento Humano.

Rua Felizardo, 750

Jardim Botânico

90690200 - Porto Alegre, RS - Brasil

Telefone: (51) 33085808 